\section{The original method for identification of abamectin and ivermectin in pharmaceutical formulations used in producing animals, using liquid chromatography coupled to ultra efficiency photodiodes: Risk assessment of pesticide residues in dairy products}

\section{Alessandra Miranda Cabral ${ }^{1}$, Maria de Fátima Vitória de Moura ${ }^{1}$, Djalma Ribeiro da Silva ${ }^{l}$, Alciney Miranda Cabral ${ }^{1}$}

Federal University at Rio Grande of Norte, Chemistry Institute,Campus Universitário, Avenida Senador Salgado Filho, 59078-970, Natal/RN, Brazil.

Alessandra_ufrnquimica@yahoo.com.br

\section{Introduction}

Avermectins are groups of macrocyclic lactones, classified as macrolides of lipophilic nature, which in mammalian organisms are metabolized, primarily, in the tissues of the liver ${ }^{1}$. The Figure 1 shows the chemical structure of compounds, the abamectin is a mixture of avermectins, containing more than $80 \%$ avermectin B1a and less than $20 \%$ B1b. These two components, B1a and B1b have biological and toxicological properties very similar ${ }^{2,3}$. The Association of Abamectin and ivermectin is an endectocide used to combat gastrointestinal and pulmonary nematode in cattle, is marketed in the form of an injectable solution. The use of this formulation is prohibited in lactating females where the milk is intended for human consumption ${ }^{4}$. However, these drugs are potent antiparasitic agents widely used in food-producing animals. Livestock farms implement manure treatment systems to increase productivity, reduce mortality, promote animal health and increase competitiveness on the market.
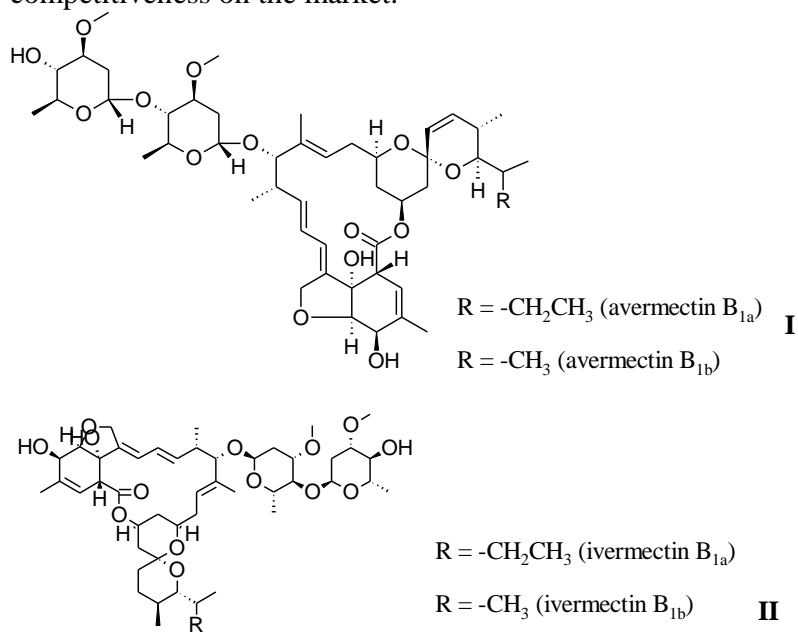

$$
\begin{aligned}
& \mathrm{R}=-\mathrm{CH}_{2} \mathrm{CH}_{3} \text { (ivermectin } \mathrm{B}_{1 \mathrm{a}} \text { ) } \\
& \mathrm{R}=-\mathrm{CH}_{3} \text { (ivermectin } \mathrm{B}_{1 \mathrm{~b}} \text { ) }
\end{aligned}
$$

Figure 1. Structure of Compounds studied abamectin (I) ivermectin (II)

The extensive use in inappropriate conditions of substance there are risks of change food security, in order to generate residues in food products, spreading into the environment and causing toxic effects, such as allergic reactions and anaphylactic shock, in consumers5. The quality assessment of these drugs proves the need to verify the safety of food and the level of environmental contamination. The Ministry of agriculture, livestock and food supply of Brazil (MAPA) implements the national plan for the Control of Residues in products of animal origin (PNCRC), because the country is the holder of an extensive cattle breeding, and one of the most important trading partners, requires this control, particularly these days, where this practice is almost an imposition in the context of international trade in food products ${ }^{6}$. The contaminant chemicals of which foods are exposed require control to ensure that they do not exceed the concentration value known as security limit or maximum residue level (MRL), that food can contain without prejudice to the organic integrity of humans, animals and the environment.

\section{Experimental}

According to the method has been designed and adapted for chromatography system UPLC-DAD. Working solutions abamectin and ivermectin were prepared were prepared in a concentration of $22.5 \mathrm{mgmL}^{-1}$ and $11.2 \mathrm{mgmL}^{-1}$, then was prepared in addition of a standard external range of $100 \mu \mathrm{gmL}^{-1}$, respectively. These solutions were ultra - sonically and filtered with $(13 \mathrm{~mm} \times 0.45 \mu \mathrm{m})$ nylon filter membrane, before Chromatographic separation that are performed in reverse-phase column C8 $(4.6 \mathrm{~mm}$ x $25 \mathrm{~cm} \times 5 \mu \mathrm{m})$ in mobile phase of water: acetonitrile $80: 20 \mathrm{v} / \mathrm{v}$ and column flow rate of $0.1 \mathrm{mlmin}^{-1}$. The wavelength was selected according to the maximum absorbance of abamectin and ivermectin in 190, 220 and $280 \mathrm{~nm}$.

\section{Results and Discussion}

In this way, the method developed is based on the identification of abamectin and ivermectin in the presence of gentamicin sulfate (substances) using liquid chromatography coupled to an ultra be fficiency photodiodes arrangement (UPLC-DAD), the chromatographic conditions are adapted to the compounds cited. Figure 2 shows the results obtained the chromatography system. The methods of analysis were based in Boisseau $1996^{7}$ they showed satisfactory results in a detection limit (LD) and quantification (LQ) with linearity of $\mathrm{R}^{2}$, it is possible to quantify the avermectines below the maximum residue limit (MRL).

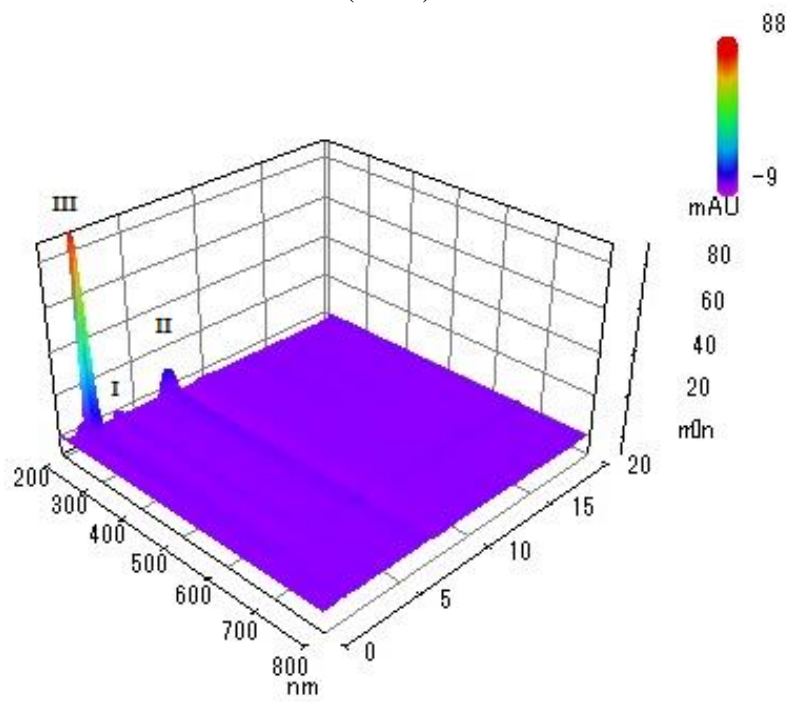

Figure 2. Chromatograms of (I) abamectin $100 \mu \mathrm{gml}^{-1}$, (II) ivermectin $50 \mu \mathrm{gml}^{-1}$ and (III) gentamicin $100 \mu \mathrm{gml}^{-1}$

Basically, the results of the simultaneous identification of compounds different classes in a single analysis with running time of 20 min, being that the sample was fortified with gentamicin gentamicin sulfate interference using as to verify the effectiveness of the method.

\section{Conclusions}

The methodology developed using UPLC-DAD is useful to quickly identify a mixture of macrolides and is considered the first step to quality control of veterinary drugs, which aims to promote safety and guarantee the minimization of waste generated in 
foodstuffs of animal origin, recommended by the PNCRC/MAPA. Therefore, this method be used as a standard inspection method to meet the requirement of the MRL set by the regulation authorities and can be extended to other macrolide antibiotics.

\section{Acknowledgement}

The authors thank the Brazilian agencies CAPES (Coordination of Improvement of Staff of Level Top) by financial promotion, The Portal Capes by virtual library, the University Federal of Rio Grande do Norte, Graduate program in chemistry and Institute of chemistry.

\section{References}

(1) Danaher. M, O'Keeffe.M, Glennon.D, Validation and robustness testing of a HPLC method for the determination of avermectins and moxidectin in animal liver samples using an alumina column clean-up. Analyst.125 (2000): 1741-1744.

(2) European Chemicals Agency (ECHA). Abamectin and Avermectin B1a: committee for risk assessment- background document to the opinion of the committee for risk assessment on a proposal for harmonised classification and labelling. 1 (2010): 1-55.

(3) Roudaut.D, Multiresidue method for the determination of avermectin and moxidectin residues in the liver using HPLC with fluorescence detection. Analyst.123 (1998):2541-2544

(4) Cheng. C, Liu. L, On-line solid-phase extraction coupled liquid chromatography-ESI-ion trap-mass spectrometry for analysis of abamectin and ivermectin residues in milk. Anal. Methods. 6 (2014): 1581-1589.

(5) Samanidou. V, Nisyriou. S, Multi-residue methods for confirmatory determination of antibiotics in milk. Journal of separation science. 31. (2008): 2068-2090

(6) Ministério da Agricultura, Pecuária e Abastecimento (MAPA). Programas de Controle de Resíduos e Contaminantes em Carnes (Bovina, Aves, Suína e Eqüina), Leite, Mel, Ovos e Pescado. Instrução Normativa 10 (2008):1-7.

(7) Boisseau. J, The abamectin residue monograph prepared by the 45 th meeting of the committee and nutrition paper. FAO. 41/8 (1996): 1-2. 